Cahiers $d u$ MONDE RUSSE

\section{Cahiers du monde russe}

Russie - Empire russe - Union soviétique et États indépendants

$59 / 4 \mid 2018$

Varia

\title{
Gleb Tsipursky, Socialist Fun
}

Youth Consumption and State-Sponsored Popular Culture in the Soviet Union, 1945-1970

\section{Gàbor T Rittersporn}

\section{(2) OpenEdition}

\section{Journals}

Édition électronique

URL : https://journals.openedition.org/monderusse/10741

DOI : $10.4000 /$ monderusse. 10741

ISSN : $1777-5388$

\section{Éditeur}

Éditions de l'EHESS

\section{Édition imprimée}

Date de publication : 1 octobre 2018

Pagination : 652-656

ISBN : 978-2-7132-2747-9

ISSN : 1252-6576

\section{Référence électronique}

Gàbor T Rittersporn, «Gleb Tsipursky, Socialist Fun », Cahiers du monde russe [En ligne], 59/4 | 2018, mis en ligne le 01 octobre 2018, consulté le 07 janvier 2022. URL : http://journals.openedition.org/ monderusse/10741 ; DOI : https://doi.org/10.4000/monderusse.10741 
Gleb TSIPURSKY

\section{Socialist Fun \\ Youth Consumption and State-Sponsored Popular Culture in the Soviet Union, 1945-1970}

Pittsburgh : University of Pittsburgh Press, 2016, 366 p.

Le terme popular culture a tout pour déconcerter les innocents qui ne sont pas familiers des bonnes manières du monde anglo-saxon. Il est fort probable qu'en premier lieu, ce terme leur évoque la culture plébéienne produite par les couches inférieures de la société. La culture plébéienne peut réagir à la culture des milieux dominants ou en emprunter des éléments, malgré tout, et bien qu'elle puisse influencer la culture savante, elle est élaborée et elle évolue parmi les masses. On l'associe à l'expression de sentiments, de passions, d'aspirations, d'affinités et d'antagonismes qui sont inséparables de l'autodéfinition implicite ou articulée d'individus et de groupes subalternes ou marginaux et à l'occasion de manifestations de tensions et de conflits sociaux. Elle apparaît dans des artefacts artisanaux et dans des œuvres de différents genres qui ne sont pas produites en série. Les créateurs et le public de la culture populaire ne sont pas strictement séparés et leurs modes de vie, leurs pratiques et leurs reflets dans le quotidien, dans les mentalités, dans les savoir-faire et dans les arts caractérisent les sociétés traditionnelles. On observe leur déclin avec les progrès de la modernité.

L'âme innocente est égarée, car force lui est faite d'admettre que la formule popular culture est relative à un phénomène qui a peu de choses en commun avec la créativité plébéienne. Il s'agit de produits de fabrication sérielle et manufacturés bien loin de tout ce qui ressemble à ce qu'on appelle, à tort ou à raison, le peuple. Ils n'expriment guère les visions du monde et l'autoperception des milieux subalternes de la société, ils servent avant tout le divertissement et ne sont que des marchandises et des services dont la nature commerciale n'est pas nécessairement évidente aux consommateurs et même à nombre de fabricants enclins à surestimer les vertus de tout ce qu'ils vendent. Theodor W. Adorno et Max Horkheimer mettent en évidence une industrie culturelle qui, sous guise de satisfaire une demande, parvient à la façonner et, dans une certaine mesure, à coloniser la vie intérieure des sujets. Ils parlent de « culture de masse », qu'ils opposent à la haute culture ou plus exactement à une haute culture aux mérites quelque peu idéalisés.

Il est devenu politiquement incorrect ne serait-ce que de faire allusion à une quelconque « culture de masse » dans le folklore intellectuel de l'Outre-Manche et de l'Outre-Atlantique. Le concept y est dénoncé comme élitiste, voire méprisant du peuple dont les goûts seraient à respecter sans réserve. Les chantres de la popular culture ne nient pas toujours le caractère commercial de l'objet de leurs méditations savantes, mais ils s'inclinent devant sa popularité. Si bien que l'esprit déconcerté soupçonne que le «populaire » est moins lié au peuple qu'au fait que la popular culture est appréciée par le public qu'elle amuse.

Il n'est pas tout à fait inutile de s'attarder sur ces détails, car le livre de Gleb Tsipursky est sur la popular culture soviétique ou plus exactement sur celle 
autorisée par l'État-Parti et confectionnée à l'usage de la jeunesse ou affectionnée par celle-ci entre la fin de la guerre et les années 1970. Il s'agit d'un objet curieux à la lumière de l'utilisation de la notion par les esprits politiquement corrects aussi bien que par les réfractaires aux bonnes mœurs. La popular culture de Tsipursky est state-sponsored, i.e. parrainée, soutenue et promue par l'État et, en fait, étroitement surveillée et contrôlée par les autorités, alors que celle du monde où le concept est né se développe et se propage au sein des structures du marché.

Quelle que soit notre opinion sur le marché en général, celui des producteurs, des marchands et des consommateurs de la culture commerciale fonctionne sans l'intervention constante de l'État. Surtout, il est libre du genre d'ingérence (souvent agressive) que Tsipursky décrit admirablement. L'un des mérites de son étude consiste à l'observation minutieuse du comportement des acteurs étatiques de la vie culturelle des jeunes en Union soviétique et à la chronique exhaustive de ses changements.

Pour le meilleur, mais aussi pour le pire, Tsipursky mesure les fluctuations de la politique culturelle avant tout à l'aune du destin mouvementé du jazz et des danses occidentales en URSS. La démarche n'est pas tout à fait injustifiée. La phobie officielle de tout ce qui rappelle les influences étrangères entre la guerre et le milieu des années 1950, ainsi que les hauts et les bas de l'expérimentation de l'adoption de modèles qu'on ne patente pas comme authentiquement soviétiques dans la période suivante, sont exemplifiés, entre autres, par les moments où les fruits interdits de sociétés méprisées et de puissances rivales sont condamnés ou reconnus, ne serait-ce qu'à contrecœur, par les responsables de l'État-Parti comme denrées consommables par la jeunesse. Les mille façons des jeunes de contourner les interdits et de déjouer la vigilance des garde-chiourmes montrent à merveille l'élasticité de pratiques sociales condamnées à tester les limites du permissible, même dans un domaine aussi banal que celui des distractions dont on souhaite remplir son temps libre. Cependant, la place disproportionnée qu'occupent le jazz, le rock et autres boogie-woogies dans le récit laissent à l'ombre d'autres phénomènes importants.

Il est au crédit de Tsipursky qu'il ne confonde pas la popularité de musiques et de danses, somme toute vulgaires, avec une résistance quelconque aux autorités. Il relève un goût juvénile de la provocation, mais il reconnaît l'attachement remarquable des jeunes au régime, surtout dans les années 1960. Tsipursky ne néglige pas d'autres domaines de la «popular culture » soviétique que ceux de la culture de masse importée. Il évoque des éléments aussi importants que le travail des maisons de la culture, des clubs et l'organisation de molodežnye kafe, des cabarets bien sages conçus pour un public jeune qui les a fréquentés avec beaucoup de plaisir. Cependant, même dans ces cas, le critère de son jugement reste l'ouverture de ces établissements au jazz ou au rock.

Il est insensible au charme de la musique de variétés et des massovye pesni, à la musique chorale aux paroles passablement édifiantes. Toutefois, les jeunes ne les détestaient pas. Ils étaient nombreux, autour des feux de camp, à chanter, accompagnés à la guitare, un répertoire allant des marches tonifiantes d'Isaak Dunaevskij et de Matvej Blanter jusqu'aux chansons sentimentales de Vasilij Solov'ev-Sedoj 
et à l'un des hits des années 1960, Que le soleil existe toujours (Pust'vsegda budet solnce) qu'Arkadij Ostrovskij et Lev Oshanin avaient pourtant écrit pour les écoles maternelles (sans oublier pour autant de glisser dans les paroles la lutte pour la paix). Tsipursky aurait pu chercher des vagues équivalentes de la musique occidentale pour compléter cet inventaire : les romances prérévolutionnaires et les blatnye pesni, chants sur le monde criminel et sur celui des camps de concentration, et s'interroger sur les origines de leur popularité.

Il néglige les voyages d'aventure et les grandes randonnées qui emmenaient d'innombrables groupes de jeunes aux quatre coins de l'empire et qui sont indissociables de la popular culture des Soviétiques. Il mentionne les groupes théâtraux en s'attardant sur un seul spectacle, mais ne consacre pas de place aux ensembles folkloriques qui façonnaient des goûts pour la culture populaire (au sens propre du terme) aussi bien que pour ses versions édulcorées ou soviétisées et pour un patriotisme aux forts accents nationalistes.

Les jeunes consommateurs du théâtre sont de grands absents. Combien de leçons n'a pas réservé l'évolution des affections de l'admiration phénoménale vouée aux péripéties amoureuses d'une prima donna et de quelques aristocrates de la monarchie austro-hongroise dans l'opérette culte d'Imre Kálmán, la Csárdásfürstin, dans les années d'après-guerre (Sil'va en URSS, Princesse Czardas en France) - les nazis n'étaient pas encore vaincus quand on en a tourné un film jusqu'au beau succès de Moskva, Cherëmushki, l'opérette de Dmitrij Šostakovič qui célèbre le grand programme de construction de logements que le régime lança à la fin des années 1950. Il manque aussi les films. Une fois de plus, l'enthousiasme pour la comédie musicale du Troisième Reich, Devuška moej mečty (Die Frau meiner Träume, La femme de mes rêves) - d'où la censure a coupé quelques cadres qu'elle trouvait osés, mais dont la diva, la vedette nazie Marika Rökk, a conquis les cœurs de centaines de milliers de filles qui voulaient lui ressembler et ceux de millions de garçons à la recherche du sex-appeal d'un étranger imaginaire dans les années 1940 et 1950 - et l'engouement à la fin des années 1960 pour le western à la soviétique qui évoque la Guerre civile, le Beloe solnce pustyni [Le soleil blanc du désert] sont des jalons qui caractérisent admirablement les changements des mœurs juvéniles et de la politique culturelle.

Il manque aussi les figures de culte. Celle de Sergej Esenin était inégalable entre les années 1920 et les années 1960 : les jeunes (et les moins jeunes) adoraient ses poèmes qui étaient peu publiés, si bien qu'ils circulaient aussi en version originale ou apocryphe sous forme de manuscrits. La nostalgie du village, le hooliganisme et la vie de fêtard qu'ils chantaient envahissaient les âmes et les suicidaires, surtout les jeunes, citaient souvent ses vers aux tendances autodestructrices dans leurs lettres d'adieu. À partir du milieu des années 1960, il céda sa place à des poètes chanteurs comme Bulat Okudžava et Vladimir Vysotskij, dont les œuvres n'étaient pas tout à fait sans sous-texte politique et, en tout cas, reflétaient une vision du monde qui n'était pas celle prônée par le Komsomol. Les lectures aussi auraient mérité quelques pages. Entre les années 1920 et 1950, des livres édifiants sur l'homme nouveau des fantasmes soviétiques comme le Que faire ? (Čto delat' ?) de Černyševskij ou le 
Et l'acier fut trempé (Kak zakaljalas' stal') de Nikolaj Ostrovskij étaient tellement populaires qu'il n'y avait guère d'albums-souvenirs de jeunes filles qui n'eussent contenu quelques citations de ces textes. À partir de la fin des années 1950 (après quelques années d'interdiction), ce sont les blagues des romans picaresques Les douze chaises (Dvenadcat'stul'ev) et Le veau d'or (Zolotoj telenok) d'Il'ja Il'f et Evgenij Petrov qui sont devenues à la mode.

L'analyse de ces changements enrichirait un ouvrage sur la culture des jeunes, ce, d'autant plus qu'elle montrerait les différences qui séparent la culture promue ou au moins tolérée par l'État soviétique de la popular culture. Même les pointilleux Adorno et Horkheimer peineraient à associer à la culture de masse certains produits que les jeunes Soviétiques ont affectionnés. Après tout, à côté de la vogue du jazz et du rock, il y avait aussi un intérêt sincère pour la musique dite classique et les opéras que des masses de jeunes venaient à estimer grâce aux places gratuites que le Komsomol offrait dans les salles de concert. Et que dire de la popularité des visites guidées dans les grands musées d'art?

Tsipursky dégage trois périodes différentes de l'approche de l'État-Parti de ce qu'il saisit comme la popular culture. L'un des points forts du livre est la distinction entre l'après-guerre avec ses tendances rigidement autoritaires, l'ère de Hruščev où les jeunes étaient encouragés à gérer eux-mêmes la consommation culturelle sous le regard relativement permissif des officiels et l'époque où le régime de Brežnev avait restreint le champ de l'initiative juvénile, surtout après la menace ressentie au moment de l'expérimentation sociale et politique en Tchécoslovaquie. Un autre aspect prometteur est la tentative de saisir le travail d'émotions partagées au sein de groupes soudés par des loisirs communs. Pour les autorités, ces loisirs devaient s'inscrire dans le projet politique du régime et en devenir indissociables. Tsipursky parle d'un « temps socialiste » que les jeunes étaient censés passer collectivement dans des clubs et dans des maisons de la culture sans qu'ils s'aperçoivent qu'il ne s'agissait pas tout à fait de temps libre. Il montre comment l'encouragement de l'initiative les rapprochait du régime et comment ils s'en éloignaient quand ils ne pouvaient plus ignorer les aspects didactiques, voire disciplinaires, d'un passe-temps qui ne les amusait pas selon leurs inclinations. L'une des conséquences de la construction en masse de logements était que les jeunes (et les moins jeunes) étaient libérés de la surveillance mutuelle des habitants des appartements communautaires et des baraques et n'étaient plus acculés à chercher des distractions dans des établissements contrôlés par l'État-Parti.

Un autre mérite du livre est qu'il explore la diplomatie culturelle pendant la guerre froide et les tentatives occidentales de séduire la jeunesse soviétique à la même époque moyennant des émissions de radio. Il cite des documents d'archives américaines et britanniques qui montrent que la diffusion de la musique de danse et de jazz faisait partie d'une stratégie pour susciter l'adhésion des jeunes Soviétiques aux valeurs du Western way of life. Tsipursky est passablement sceptique quant au succès de l'opération. Ses recherches ne permettent pas de conclure que les admirateurs de la musique occidentale auraient associé une dimension politique à leur passion dans la période qu'il a étudiée. 
Tsipursky pense que la popular culture soviétique faisait partie de ce qu'il dénomme la « modernité socialiste ». Il semble oublier que quelque chose est moderne ou ne l'est pas, de sorte que le socialisme n'explique pas grand-chose du phénomène. La modernité est plutôt capitaliste, car elle se matérialise dans les sociétés de consommation de type industriel et postindustriel. Elle est caractérisée par l'inscription des individus, des groupes et des catégories sociales dans un système cohérent de technostructures, d'administrations, de procédés d'éducation, de production, de distribution et de consommation, ainsi que par l'intériorisation, par les sujets conditionnés, des règles et des normes du fonctionnement de ce système et des valeurs explicites et implicites qui lui sont inhérentes s'ils aspirent à des statuts sociaux un tant soit peu avantageux. La majorité des individus s'intègre dans les structures de la modernité sans se rendre compte des contraintes qu'elle impose. La condition moderne n'est pas caractérisée par la répression ouverte : elle déploie de la force seulement aux moments de crise et envers des éléments marginaux ou des minorités qui ne s'y adaptent pas ou qui sont jugés inadaptables.

Le système soviétique n'a jamais réussi à élaborer des structures et des mécanismes qui auraient adapté les individus et les groupes à son fonctionnement et à la pression ouverte de mesures administratives et pénales. Tsipursky lui-même le montre quand il décrit les agissements, parfois ubuesques, des autorités pour encadrer même les loisirs de la jeunesse. La modernité a réduit à néant la culture populaire traditionnelle, alors que certains de ses éléments comme les častuški ou les anecdotes politiques ont perduré en Union soviétique jusqu'à sa fin. Fait peu étudié : des poèmes aux sujets politiques — les frasques attribuées à Madame Gorbačev en ont été l'un des thèmes - ont circulé sous la forme de manuscrits jusqu'à la fin des années 1980.

Malgré tout, le livre de Tispursky est éclairant. Il convainc le lecteur que même des passe-temps passablement réglementés suffisaient pour laisser penser aux Soviétiques que leur consommation culturelle, qui était en partie un moyen de surveillance, faisait partie des grands acquis du système. Elle a contribué à la stabilité du régime jusqu'à sa crise finale à partir des années 1970.

Gàbor Rittersporn

CERCEC, CNRS, EHESS, PSL 